WMJ (Warmadewa Medical Journal), Vol. 1 No. 2 November 2016, Hal. 51-57

\title{
Kemudahan dan Efek Samping Penggunaan Inserter Baru ( $R$ _inserter) Untuk Pemasangan IUD CuT-380A Pascasalin
}

\author{
Kadek Agus Kurniawan \\ Fakultas Kedokteran dan Ilmu Kesehatan Universitas Warmadewa, \\ Jl Terompong No. 24 Tanjung Bungkak. Denpasar \\ Email: kadekaguskurniawan@gmail.com
}

\begin{abstract}
Abstrak
Latar belakang penelitian ini didasari oleh penggunaan IUD di Indonesia yang relatif rendah yakni $7,2 \%$ dari seluruh pemakaian alat kontrasepsi. Selama ini pemasangan IUD yang baku adalah mengunakan prinsip "no touch and withdrawl technique". IUD pascasalin yang sekarang digunakan adalah IUD biasa dimana panjang insertor tidak sesuai dengan kedalaman rongga rahim sehingga prinsip di atas tidak bisa dilakukan, dan keadaan ini dapat meningkatkan risiko infeksi. Oleh karena itu penulis berusaha membuat insertor baru yang sesuai dengan kedalaman uterus pascasalin. Tujuannya untuk mengetahui apakah IUD $R \_$inserter baru ini bisa dipasang secara no touch dan withdrawl technique dengan mudah dan untuk mengetahui efek samping yang terjadi. Metode yang digunakan merupakan Uji klinis fase II, post test observation. Selama kurun waktu 9 bulan pengamatan diperoleh 142 klien yang memenuhi kriteria penelitian. Lama pemasangan rata-rata adalah 3,89 $\pm 2,08$ menit dengan minimum 2 menit dan maksimum 10 menit. Tidak ada kesulitan yang dirasakan. Secara kumulatif kejadian ekspulsi dalam 3 dan 6 bulan masing-masing 9,9\% dan 10,6\%. Kejadian seperti nyeri, perdarahan dan infeksi relatif lebih kecil dan dapat diatasi. Angka kelangsungan selama 3 dan 6 berturut turut adalah $89,4 \%$ dan 86,6\%. Tidak dijumpai perforasi dan kehamilan pada penelitian ini. Adapun kesimpulan yang bisa didapat dari IUD $R_{-}$Inserter baru dapat dipasang dengan mudah. Angka kejadian tertinggi adalah ekspulsi terjadi dalam satu bulan pertama pasca pasang.
\end{abstract}

Kata kunci: $R \_$inserter, ekspulsi, angka kelangsungan.

\begin{abstract}
[The Easiness and Side Effect Using New Inserter ( $R$ _inserter) for Insertion of CuT-380A IUD During Postpartum Periods].

Background of this study is the fact that the rate of IUD use in Indonesia is relatively low at $7.2 \%$ among all contraceptive users. The standard insertion of IUD should be a no touch and withdrawal technique. With the conventional inserter this IUD is not able to use during postpartum period. The new inserter should be devised. Objective of the study was to find out whether the new $R_{-}$inserter could be used to insert IUD during postpartum period in no touch and withdrawal technique easily and to find out side effects and complication that might occur. Design for this study was phase II clinical trial, post test observation. During 9 months period of study has recruited as many as 142 clients who meet the eligibility criteria. Mean duration of insertions was 3,89 $\pm 2,08$ minutes, with the minimum 2 minutes and the maximum 10 minutes. No difficulties were perceived by insertors. Cumulative expulsion rates were $9.9 \%$ and $10.6 \%$ for 3 and 6 months respectively. Continuation rates were $89.4 \%$ and $86.6 \%$ for 3 and 6 months respectively. No perforations, no pregnancy was found during this study. The conclusion is the new $R$ inserter could be used easily for $C u T$ insersions. The highest incidence rates are expulsion occured in the first month after insersions.
\end{abstract}

Keywords: $R$ _inserter, expulsion, continuation rate. 


\section{PENDAHULUAN}

Indonesia sekarang (2011) dengan jumah penduduk sebanyak 237 juta jiwa menempati negara dengan jumlah penduduk terpadat ke 4 setelah Cina $(1,339,240,000)$, India $(1,184,766,000)$, dan Amerika Serikat $(310,000,000)^{[1]}$. Pada tahun 2007 jumlah penduduk miskin mencapai $15,58 \%$ dari total penduduk atau sebesar 37,168 juta jiwa ${ }^{[2]}$ dan pada tahun 2010 diperkiran telah menurun menjadi 31,03 juta jiwa sebuah penurunan yang dinilai lambat. ${ }^{3}$ Jumlah penduduk besar dengan kualitas kurang merupakan sebuah beban pembangunan sehingga laju pertumbuhan penduduk harus dikurangi ${ }^{[1]}$.

Penggunaan IUD (intra-uterine device, atau alat kontrasepsi dalam rahim) sebagai alat kontrasepsi di Indonesai relatif masih sangat rendah yakni $7,2 \%$ dari seluruh pemakaian alat kontrasepsi, lebih kecil dibanding pemakaian suntikan $(58,4 \%)$, pil $(24 \%)^{[2]}$ padahal sebagai alat kontrasepsi IUD memenuhi beberapa syarat seperti murah, efektif, praktis, dan mudah pemasangannya jika diberikan pelatihan yang memadai untuk para petugasnya. Berdasarkan Survei Demografi dan Kesehatan Indonesia (SDKI) 1987, jumlah persalinan di Indonesia mencapai 5,7 juta per tahun, dan 70\%-nya ditangani di fasilitas kesehatan. Andaikata 10\% dari ibu postpartum ini bisa terlayani dengan KB IUD pascasalin maka kontribusi IUD untuk seluruh pemakaian alat kontrasepsi akan meningkat secara bermakna ${ }^{[2]}$.

Pemasangan IUD pascasalin yang dilakukan mempunyai keuntungan antara lain mudah pemasangannya, akseptor jelas tidak dalam keadaan hamil, tidak memerlukan waktu tertentu lagi, dan pasien sudah terlindungi segera setelah meninggalkan rumah sakit. Meskipun demikian IUD tidak boleh dipasang tanpa konseling yang cukup dan informed consent dari pihak pasien. Untuk tujuan tersebut sabaiknya konseling tentang pemasangan IUD pasca pelepasan plasenta dan IUD pascasalin pada umumnya telah dilakukan dengan baik sejak ibu hamil dalam asuhan antenatal. Konseling yang dilakukan saat pasien dalam persalinan sering menyebabkan penyesalan karena keputusan diambil dalam suasana yang tidak kondisif. Bagi calon klien yang belum mendapatkan konseling awal sebaiknya konseling dilakukan setelah ibu terbebas dari stres dan kecemasan akibat proses persalinan. Teknik pemasangan IUD telah dibakukan yakni mengunakan "no touch and withdrawl technique". Untuk IUD Tcu-380A, lengan IUD harus dimasukkan dalam insertor di dalam bungkusnya dan sama sekali tidak boleh disentuh dengan tangan meskipun tangan dalam keadaan steril. Selanjutnya IUD dimasukkan kedalam uterus melalui kanalis servikalis juga tidak boleh menyentuh dinding vagina. Selanjutnya IUD ditempatkan di fundus, ditahan dengan pendorongnya, insertor ditarik sedikit sehingga IUD terlepas. IUD didorong sedikit ke atas agar mepet ke fundus dan selanjutnya seluruh selongsong dengan pendorongnya ditarik ke luar dan radiks dipotong secukupnya ${ }^{[3]}$.

IUD yang dipasang pascasalin sampai sejauh ini masih menggunakan IUD biasa yang dipasang dengan 2 cara. Cara pertama adalah dijepit dengan menggunakan 2 jari dan dimasukkan ke dalam rongga uterus melalui serviks yang masih terbuka sehingga seluruh tangan bisa masuk. IUD diletakkan tinggi menyentuh fundus uterus. Cara kedua dengan menggunakan klem cincin (ring forceps) di mana IUD dipegang pada pertemuan antara kedua lengan horizontal dengan lengan vertikal dan diinsersikan jauh ke dalam fundus uterus. Kedua cara ini menyalahi prinsip "no touch and withdrawl technique" sehingga berpotensi menaikkan risiko infeksi. Cara demikian ditempuh karena IUD yang tersedia di pasaran memang bukan IUD yang dirancang khusus sebagai IUD pascasalin.

Masalah yang timbul adalah prinsip "no touch and withdrawl technique" ini tidak bisa diterapkan di sini karena insertor kurang panjang untuk uterus pascasalin. Panjang insertor IUD TCu-380A yang tersedia dipasar produksi PT Kimia Farma adalah $20,5 \mathrm{~mm}$ sehingga bila dipasang 
dengan cara "no touch and withdrawl technique" tidak memungkinkan, karena seluruh insertor masuk kedalam vagina dan tidak ada bagian yang dapat dipegang.

Berdasarkan penelitian yang kami lakukan sebelumnya, diperoleh data bahwa kedalaman rahim sampai dengan muara vagina (introitus vagina) rata-rata adalah 20 $\mathrm{cm}$ dengan nilai maksimum $28 \mathrm{~cm}$. Atas dasar itulah kami dengan didukug oleh PT Kimia Farma Indonesia merancang sebuah IUD TCu-380A dengan panjang insertor 28 $\mathrm{cm}$ dan diameter insertor $1 \mathrm{~mm}$ lebih lebar dibandingkan IUD TCu-380A standard. Dengan demikian proses memasukkan IUD dalam insertor lebih mudah dan no-touch technique bisa dilakukan.

Penelitian ini dimaksud untuk mengetahui apakah IUD yang baru dapat dipasang dengan mudah dan untuk mengetahui efek samping yang terjadi, yang meliputi angka nyeri, angka ekspulsi, angka translokasi, angka infeksi, angka perdarahan, dan angka perforasi

\section{METODE}

Jenis IUD ini adalah TCu-380A yang mengalami modifikasi pada panjang dan diameter insertor. Karena penelitian yang menyangkut bagaimana kemudahan memasang IUD jenis ini segera setelah plasenta lepas belum pernah dilakukan, maka penelitian yang kami lakukan ini adalah uji klinis fase II, sehingga tidak diperlukan adanya kontrol. Desain yang dipakai adalah post test observation.

Penelitian dilakukan di RS Sarjito dengan beberapa RS dan Puskesmas jejaring. Ada 4 RS dan 3 Puskesmas dengan perawatan yang dipakai pada penelitian ini yakni RS Sardjito, RS Cilacap, RS Wonosobo, PKM Mergangsan, PKM Jetis, PKM Tegalrejo.

Kriteria inklusi meliputi semua pasien pascasalin yang membutuhkan IUD sebagai alat kontrasepesi, kontraksi uterus pasca lepas plasenta kuat, tidak ada perdarahan vaginal dan bersedia melakukan follow up. Tidak masuk dalam penelitian adalah persalinan vaginal traumatis sehingga membutuhkan waktu segera untuk melakukan penjahitan pada luka didaerah vulva dan vagina, misal ruptur perineum derajat 3 dan 4.

Pemasangan dilakukan oleh Residen semester IV atau Bidan yang telah dilatih dengan menggunakan standar no touch and withdrawl technique. Segara setelah plasenta lahir dan kontraksi uterus baik, penolong berganti sarung tangan. Dalam posisi litotomi, speculum Sims dipasang, bibir depan serviks dijepit dengan klem cincin, dan IUD diinsersi melalui kanalis servikalis sampai fundus. Dengan standar no touch and withdrawl technique IUD dilepas ke dalam kavum uteri. Benang IUD baru dipotong pada kunjungan ulang satu minggu.

\section{HASIL}

Penelitian dilakukan di 5 tempat dengan masing-masing jumlah aksetor yaitu: RS Sardjito (10 Akseptor), RS Cilacap (10 Akseptor), PKM Mergangsan (92 Akseptor), PKM Tegalrejo Akseptor) dan RSU Wonosobo Akseptor).

Pemasangan IUD pascasalin pertama dilakukan di RSU Wonosobo pada tanggal 17-12-2011 dan berakhir pada tanggal 1-42012 di PKM Mergangsan. Follow up terakhir adalah tangal 31 Desember 2012. Selama kurun waktu 3 bulan diperoleh 142 klien yang memenuhi kriteria inklusi dan eksklusi.

Data demografi klien pada penelitian ini didapatkan umur rata-rata adalah 27,8 tahun dengan umur termuda 14 tahun dan umur tertua 40 tahun. Sebagian besar akseptor berumur antara 20-35 tahun yang merupakan umur reproduksi sehat. Sebagian besar klien baru mempunyai seorang anak sebanyak 51 orang, dengan 2 anak 31 orang dan sebagian kecil mempunyai anak tiga atau lebih sebanyak 18 orang.

\section{Lama Pasang IUD}

Pada waktu melakukan pemasangan IUD, Penulis juga menghitung lama memasukkan IUD pada klien adalah waktu yang dihitung sejak spekulum masuk sampai inserter ditarik. Pada penelitian ini 
lama pasang minimal 2 menit dan maksimal 10 menit dengan rata-rata lama 3,86 $\pm 2,05$ menit ,tidak ada kesulitan yang dirasakan oleh insertor.

Pemasangan IUD pascalepas plasenta adalah pemasangan yang dilakukan dalam 10 menit pertama setelah plasenta lahir. Pada penelitian ini dari 137 kasus 78\% dipasang dalam waktu 10 menit pertama sedangkan $22 \%$ dipasang setelah lebih dari 10 menit. Pemasangan paling lama dilakukan 72 jam pascasalin.

\section{Angka Kejadian}

Pada follow up satu minggu, kejadian efek samping yang paling sering adalah ekspulsi yang mencapai $8,5 \%$ sedangkan infeksi sebesar $0,7 \%$, nyeri sebesar 3,5\% dan tidak didapatkan kejadian perdarahan dan lepas karena alasan medis.

Pada follow up 1 bulan kejadian yang masih dijumpai adalah nyeri, ekspulsi, dan perdarahan masing-masing $1,5 \%$ sedangkan infeksi dan lepas dengan alasan medis masing-masing $0,8 \%$ yakni pasien yang IUD dilepas karena alasan medis, yakni infeksi dan nyeri yang tidak sembuh dengan pemberian antibiotika dan analgetika.

Pada follow up 2 bulan dan 3 bulan kejadian yang masih dijumpai hanya perdarahan sebesar $0,8 \%$.

Pada follow up 4 bulan dan 5 bulan hanya didapatkan kejadian perdarahan sebesar 3,9\%, kejadian ekspulsi, infeksi, lepas karena alasan medis masing-masing sebesar $0,8 \%$ sedangkan kejadian nyeri sebesar $3,1 \%$.

Pada terakhir follow up 6 bulan tidak didapatkan kejadian ekspulsi dan infeksi sedangkan untuk kejadian perdarahan didapatkan sebesar 2,4\%, nyeri sebesar $0,8 \%$ dan lepas karena alasan medis sebesar 1,6\% (Gambar 1).

Selanjutnya secara kumulatif, kejadian pada follow up 3 bulan dan 6 bulan terlihat pada Gambar 2.

Sementara itu, selama 6 bulan pengamatan beberapa akseptor tidak lagi memakai IUD dengan berbagai alasan seperti ekspulsi, dilepas karena alasan nyeri dan infeksi yang tidak sembuh dengan pemberian analgetika dan antibiotika. Sehingga angka kelangsungan pemakaian selama 3 bulan sebesar $89,4 \%$ dan 6 bulan sebesar $86,6 \%$.

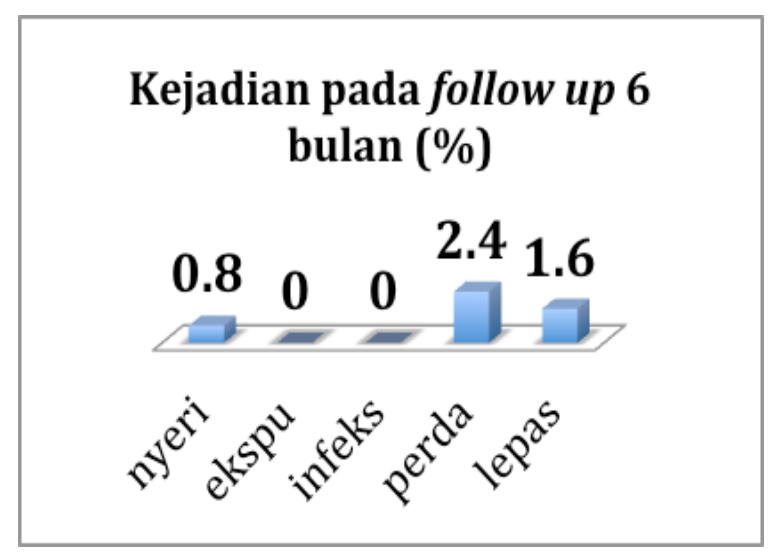

Gambar 1. Angka Kejadian pada follow up 6 bulan.

\section{Kejadian Kumulatif (\%)}


\section{3 bulan 6 bulan}

Gambar 2. Kejadian kumulatif pada follow up 3 bulan dan 6 bulan.

Satu fenomena yang menarik adalah angka ekspulsi tertinggi terjadi di RSU Wonosobo, yakni 7 dari 10 akseptor (70\%). Keseluruhan akseptor mengalami ekspulsi dipasang oleh satu orang residen. Jika akseptor dari RS Wonosobo tidak diperhitungkan maka kejadian ekspulsi adalah 7 dari 142 akseptor atau sama dengan 5,3\%, sebuah angka ekspulsi yang rendah.

$$
\text { Saat pemasangan ternyata }
$$
mempengaruhi kejadian ekspulsi. Tabel berikut menunjukkan bahwa saat pemasangan lebih dari 10 menit meningkatkan risiko ekspulsi sebesar 3,9 kali (Tabel 1). 
Tabel 1. Pengaruh saat pemasangan terhadap kejadian ekspulsi.

\begin{tabular}{lllll}
\hline \multirow{2}{*}{$\begin{array}{c}\text { Saat } \\
\text { pemasangan }\end{array}$} & \multicolumn{2}{l}{ Ekspulsi } & & \multirow{2}{l}{ RR (95\%) } \\
\cline { 2 - 3 } & Ya & Tidak & & \\
\hline$>10$ menit & 7 & 22 & 24,1 & 3,90 \\
$\leq 10$ menit & 7 & 106 & 6,2 & $(1,37-11,12)$ \\
\hline
\end{tabular}

Untuk mengetahui pengaruh paritas terhadap kejadian ekspulsi, maka dibuat tabel silang sebagai berikut (Tabel 2).

Tabel 2. Pengaruh paritas terhadap kejadian ekspulsi.

\begin{tabular}{lllll}
\hline \multirow{2}{*}{ Paritas } & \multicolumn{2}{l}{ Ekspulsi } & \multirow{2}{*}{$\%$} & \multirow{2}{*}{ RR (95\%) } \\
\cline { 2 - 3 } & Ya & Tidak & & \\
\hline Primipara & 8 & 68 & 10,5 & 0,85 \\
Multipara & 6 & 60 & 9,1 & $(0,28-2,59)$ \\
\hline
\end{tabular}

\section{PEMBAHASAN}

Lama pemasangan IUD dengan inserter baru bervariasi antara 2 sampai 10 menit dengan rata-rata 3,86 menit. Pemasangan yang relatif agak lama pada umumnya berasal dari residen yang baru pertama memasang, meskipun mereka telah mendapat pelatihan sebelumnya. Pada umumnya mereka tidak mengalami kesulitan sama sakali, dan tidak ada IUD yang tertarik pada saat melepas inserter. Demikian juga tidak ada klien yang mengeluh sakit pada saat pemasangan. Dengan demikian dapat disimpulkan bahwa pemasangan IUD dengan inserter baru cukup mudah dan nyaman buat klien.

Penelitian multisenter pertama tentang pemasangan IUD pascalepas plasenta dilakukan pertama kali pada akhir tahun 1970-an yang melibatkan 841 wanita. Tiga bentuk IUD digunakan yakni Postpartum T, Lippes Loop D (LLD), dan Coper 7-200 (Cu7-200). Tidak terjadi perforasi uterus dalam penelitian ini. Pada 12 bulan observasi, angka kehamilan untuk Postpartum T, LLD, dan Cu7-200 berturutturut adalah 5,6, 12,1 dan 7,3 per 100 wanita. Penelitian ini dihentikan karena angka kehamilan dan ekspulsi melebihi batas yang ditetapkan dalam protokol penelitian yakni angka kehamilan kurang dari 3 dan angka ekspulsi kurang dari 20 per 100 women-years ${ }^{[4,12]}$.

Angka kejadian utama pada penelitian ini adalah ekspulsi yang terjadi terutama pada satu bulan pasca pasang yang mencapai 9,9\% dan secara kumulatif pada 6 bulan pasca pasang adalah $10,6 \%$. Dalam sebuah penelitian di China, Xu dkk , menunjukkan bahwa tidak ada perbedaan dalam angka ekspulsi antara pemasangan IUD menggunakan tangan dibanding menggunakan klem cincin. Angka ekspulsi dari kedua cara tersebut mencapai10,8\% (95\% CI 8,02 -13,76) pada pemasangan dengan tangan dan $11,8 \%$ (95\% CI 8,31 14,24) ${ }^{[4,5]}$. Sebuah review oleh WHO menunjukkan bahwa ekspulsi memang menjadi perhatian utama karena angkanya yang relatif tinggi yakni antara 6\% sampai $44,1 \%$ pada kurun waktu pemakaian 6 sampai 36 bulan ${ }^{[3]}$. Penelitian lain menunjukkan memang angka ekspulsi pada pemasangan segera pascasalin mempunyai risiko 6,77 kali $(95 \%$ CI $1,43-32,14)$ dibanding pemasangan pascalepas plasenta $[6,7,13]$.

Angka perdarahan sampai 6 bulan pada penelitian ini adalah $2,4 \%$ dan hanya bersifat menoragi yang tidak dirasakan terlalu mengganggu, karena tidak ada yang meminta untuk dilepas kecuali satu akseptor karena disertai infeksi endometritis. Sebuah systematic review menunjukkan angka yang lebih rendah yakni hanya $2,0 \%{ }^{[8,9]}$. Di samping perdarahan satu efek samping lain yang mengganggu adalah infeksi yang terjadi 1 minggu pasca pasang sebesar $0,7 \%$ sedangkan dalam 1 bulan dan 5 bulan masing-masing $\quad 0,8 \%$. Pasien yang menderita infeksi akhirnya dilepas karena tidak respons dengan pemberian antibiotika sehingga secara kumulatif angka pelepasan IUD dalam 6 bulan sebesar 2,8\%.

Angka kelangsungan pemakaian IUD selama tiga bulan adalah $89,4 \%$ dan pada enam bulan menurun sampai $86,6 \%$ pada akhir penelitian. Alasan utama mereka berhenti menggunakan IUD adalah ekspulsi, nyeri dan infeksi. Sebuah review menunjukkan bahwa continuation rate 
bervariasi antara 57\%, 84\% dan 93,3\% [3]. Tidak terdapat kehamilan pada penelitian ini meskipun sebuah review mengatakan kehamilan bervariasi antara 0 sampai $12,1 \%$ [6]. Tidak adanya kehamilan pada penelitian ini mungkin berhubungan dengan periode pascasalin itu sendiri ${ }^{[10,11]}$.

Laporan dari sebuah jurnal Cochrane review mengenai immediate post-partum insertion of intrauterine devices menunjukkan kesimpulan sebagai berikut [9]:

a. Pada umumnya pemasangan IUD pascasalin adalah aman dan efektif. Angka ekspulsi pada semua penelitian selalu lebih tinggi pada follow up 3 bulan dibandingkan setelahnya.

b. Satu penelitian IUD yang didalamnya terdapat kandungan levonorgestrel menunjukkan bahwa angka ekspulsi setelah enam bulan pada pemasangan IUD pascasalin dibanding pemasangan dalam masa nifas adalah masing-masing $23.5 \%$ vs $4.4 \%$ dengan OR 6.77 ( $95 \%$ CI: 1.43-32.14). Tidak dijumpai kehamilan sampai 6 bulan tetapi angka kelangsungannya masing-masing adalah $84 \%$ dan $77 \%$.

c. Pada Follow up awal tiga bulan dikombinasi dengan pemeriksaan benang oleh klien sendiri dapat membantu deteksi adanya ekspulsi spontan.

\section{SIMPULAN}

IUD pascasalin dengan ( $R$ inserter) baru dapat dipasang dengan muda $\bar{h}$. Angka kejadian efek samping yang utama adalah ekspulsi yang kejadiannya terbanyak pada satu bulan pasca pemasangan sebesar 1,5\%. Efek samping lain adalah nyeri dimana ada empat kasus dilakukan pelepasan yang tidak dapat diatasi dengan pemberian analgetika. Ada satu kasus pelepasan IUD terjadi karena infeksi yang tidak sembuh dengan pemberian antibiotika saja. Angka kelangsungan pemakaian kumulatif pada 6 bulan pemakaian sebesar $86,6 \%$ masih berada pada rentang peneliti lain dan tidak ada kehamilan selama 6 bulan pengamatan.
Diperlukan penelitian lebih lanjut uji klinis fase III untuk membandingkan secara langsung antara IUD ( $R$ _inserter) baru dengan IUD konvensional yang telah ada sebelumnya.

\section{UCAPAN TERIMAKASIH}

Penulis mengucapkan terima kasih kepada semua pihak yang telah membantu karya ilmiah akhir ini. Kepada DR. dr. Heru Pradjatmo, M. Kes., SpOG(K) selaku Kepala Bagian Obstetrika dan Ginekologi dan dr. Irwan Taufiqur Rachman, $\operatorname{SpOG(K)}$ selaku Ketua Program Studi Obstetrika dan ginekologi FK UGM/RSUP Sardjito, secara khusus ucapan terima kasih penulis tujukan kepada dr. H. Risanto Siswosudarmo, SpOG $(K)$, selaku pembimbing materi dan dr. Ahsanuddin Attamimi, SpOG(K), selaku pembimbing metodologi. Kepada seluruh Staf Pengajar bagian Obstetri dan ginekologi FK UGM/RSUP Sardjito serta RS Afiliasi Pendidikan, Dekan FK UGM, Direktur RS Sardjito beserta jajarannya, karyawan/paramedis, sejawat residen, pasien atas kerja samanya, PT Kimia Farma yang telah membuat IUD pascasalin dengan inserter baru sesuai dengan spesifikasi yang telah kami minta, BKKBN Indonesia yang telah memberikan dukungan sehingga penelitian ini berjalan dengan lancar.

\section{DAFTAR PUSTAKA}

\section{SDKI Indonesia Demographic and Health Survey 2012. BPS,} BKKBN,Kemenkes and ICF International. Jakarta, Indonesia.

2. Hartanto, H. Keluarga Berencana dan analisis epidemiologi kontrasepsi. 2007; 28:112-30.

3. Siswosudarmo, HR 2011. Pengukuran kedalaman Uterus Pascasalin. Bagian Obstetri dan Ginekologi Fakultas Kedokteran UGM - RS Sardjito Jogjakarta.

4. $\mathrm{Xu}$ JX, Reusche $\mathrm{C}$ and Burdan A. Immediate postplacental insertion on the intrauterine device: a review of Chinese and the world experience. Advance in Contraception. 1994;10:71-82v. 
5. Xu JX, Rivera R, Dunson TR, Zhuang LQ, Yang L, Ma T and Chi I-c. A Comparative study of Two Techniques Used in Immediate Postplacental Insertion (IPPI) of the Copper T-380A IUD in Shanghai, People's Republic of China. Contraception. 1996;54:33-38.

6. Chi IC, Wilkins L, Rogers S. Expulsions in immediate postpartum insertion of Lippes Loop D and CopperT IUDs and their counterpart Delta devices: an epidemiological analysis. Contraception. 1985; 32:119-34.

7. Chi IC, Farr G, Dominik R, Robinson N. Do retroverted uteri adversely affect insertions and performance of IUDs? Contraception. 1990;41:495-506.

8. Grimes, D.A., Schulz, K.F., Van Vliet, H., Stanwood, N., Lopez, L.M. 2007. Immediate post-partum insertion of intrauterine devices (Review). Cochrane Database Syst Rev:1-19

9. Grimes DA, Lopez LM, Schulz KF, Van Vliet HAAM, Stanwood NL. Immediate post-partum insertion of intrauterine devices. Cochrane Database of Systematic Reviews 2010, Issue 5. Art. No.: $\quad$ CD003036. DOI: 10.1002/14651858.CD003036.pub2.

10. Kaneshiro B, Jensen J, Edelman A. Copper T380A intrauterine device: lost and found. Hawaii Med J. 2008;67:131-
132.

11. Kaneshiro B, Aeby T. Long-term safety, efficacy, and patient acceptability of the intrauterine Copper T-380A contraceptive device. Int $\mathrm{J}$ Womens Health 2010; 2: 211-220.

12. Meirik, O., Rowe, P.J., Peregoudov, A., Piaggio, G., Petzold, M. The frameless copper IUD (GyneFix) and the Tcu380A IUD: results of an 8-year multicenter randomized comparative trial. 2009;80 (2):133-141.

13. Hayes JL, Cwiak C, Goedken P and Zieman M. A pilot clinical trial of ultrasound-guided postplacental insertion of a levonorgestrel intrauterine device. Contraception. 2007;76: 292296. 